\title{
Intercellular signaling and the polarization of body axes during Drosophila oogenesis
}

\author{
Robert P. Ray and Trudi Schüpbach \\ Department of Molecular Biology, Howard Hughes Medical Institute, Princeton University, \\ Princeton, New Jersey 08544 USA
}

The anterior-posterior and dorsal-ventral axes of the Drosophila egg and embryo are established during oogenesis as the egg is being formed. The mechanisms underlying this process involve intercellular signaling events, including bidirectional communication between germline and somatic cells, and local cell-cell interactions in the soma. On the molecular level, these interactions appear to be mediated by a small number of intercellular signaling systems, including the Epidermal growth factor receptor (Egfr) and Notch systems, that are used multiple times during oogenesis to trigger different developmental switches. The precisely regulated interplay between these various signaling systems forms a network of interdependencies that leads to the establishment of both the anterior-posterior and dorsal-ventral polarity in the egg chamber and embryo. Because both the Egfr and Notch signaling systems are widely conserved, the mechanisms involved in the regulation of these processes in Drosophila oogenesis may serve as a paradigm for understanding intercellular signaling events in other organisms.

\section{Maternal determinants, embryonic patterning, and oogenesis}

In the Drosophila embryo, the specification of pattern elements along the anterior-posterior and dorsal-ventral axes is controlled by a small number of maternal gene products that are either spatially localized or locally activated in the egg (for review, see St. Johnston and Nüsslein-Volhard 1992). Anterior-posterior patterning of the segmented region of the embryo depends on the localization of two maternal mRNAs, bicoid (bcd) at the anterior pole and nanos (nos) at the posterior pole, that serve as localized sources for protein gradients that regulate transcription (bcd) or translation (nos) of target genes in early embryogenesis. Specification of the terminal segments and of the dorsal-ventral pattern depends on the localized activation of uniformly distributed cellsurface receptors torso (tor) and Toll $(T l)$, respectively. For the latter, it is known that receptor activation leads to the formation of an activity gradient of dorsal (dl) protein that differentially regulates zygotic gene expression along the axis.
The localization of bcd and nos mRNAs and the production of the positional cues that restrict activation of the receptors tor and $T l$ occur during oogenesis when the egg is being built. The basic unit of Drosophila oogenesis is the egg chamber (Fig. 1), which will give rise to a single egg (for review, see Spradling 1993). An egg chamber is a composite of germ-line and somatic cells, consisting of 16 interconnected germ-line cells (15 nurse cells and a posteriorly positioned oocyte), that are enveloped in an epithelium of somatic follicle cells. In the ovary, the egg chambers are arranged in linear structures called ovarioles that are divided into two compartments: the germarium, at the anterior tip, where the egg chambers are formed, and the vitellarium, extending to the posterior, where they develop into mature eggs. Anterior-posterior and dorsal-ventral asymmetries become apparent at different times during oogenesis. Anterior-posterior asymmetry is first evident in the germarium, when the oocyte assumes its characteristic position at the posterior of the germ-line cluster. Dorsal-ventral asymmetry is not apparent until mid-oogenesis when the oocyte nucleus moves from its initial position in the oocyte to an anterior corner that subsequently becomes the dorsal side. The establishment of anterior-posterior polarity appears to be a regulated process in that the new axis is invariably aligned with respect to the anterior-posterior axes of the other egg chambers and of the ovary. By contrast, the establishment of dorsal-ventral polarity appears to be stochastic insofar as the individual egg chambers do not orient the new axis with respect to any visible asymmetry in the ovary.

\section{The torpedo/DER signaling system and dorsal-ventral patterning}

The Egfr signaling system plays a central role in the establishment of polarity and the localization of cytoplasmic determinants during oogenesis. The receptor in this system, Egfr (also called torpedo/DER), is the Drosophila homolog of the vertebrate EGF receptor, and thus belongs to the receptor tyrosine kinase (RTK) family of trans-membrane receptor proteins (Livneh et al. 1985; Wadsworth et al. 1985). In addition to its role in oogenesis, Egfr is involved in intercellular signaling events in 

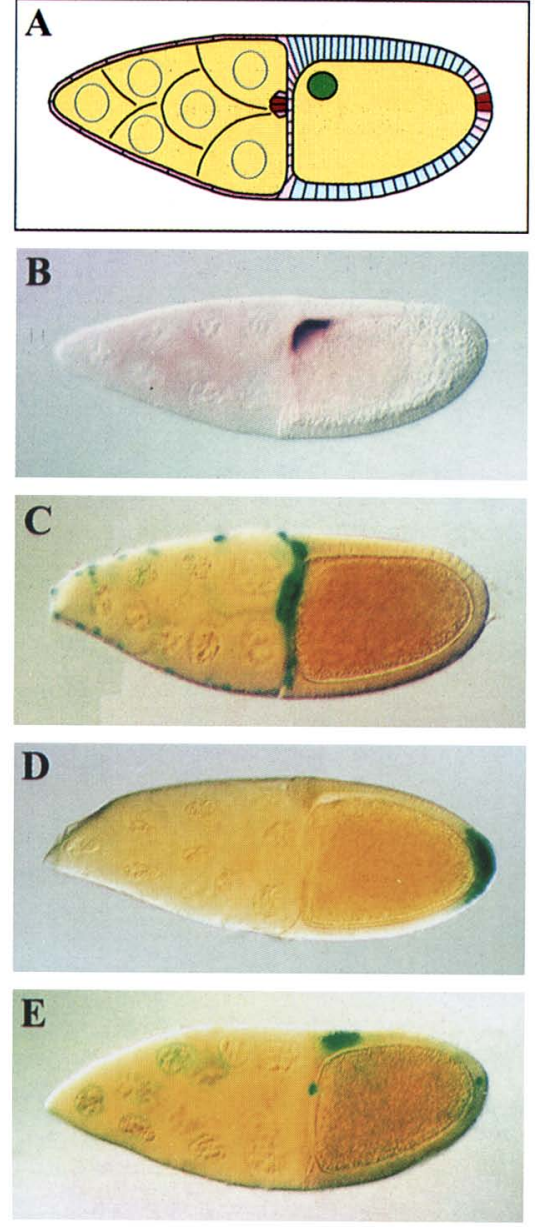

Figure 1. Different cell types in the Drosophila egg chamber. (A) Schematic diagram of a Drosophila egg chamber with different cell types color-coded. Germ-line cells appear in yellow, the nurse cells at the anterior end, and the oocyte at the posterior. The oocyte nucleus is shown in green. Follicle cells are subdivided into three cell types: main body follicle cells in blue, terminal follicle cells in pink, and the pairs of polar follicle cells in red. $(B)$ A wild-type egg chamber showing the localization of grk mRNA to the dorsal-anterior corner of the oocyte in close proximity to the asymmetrically positioned oocyte nucleus. $/ \mathrm{C}-$ $E$ ) Enhancer-trap lines stained for $\beta$-galactosidase activity (in blue) that mark different subpopulations of follicle cells. Enhancer trap line B22 $(C)$ marks the anterior terminal follicle cells, including the border cells and centripetal follicle cells that are at the interface between nurse cells and oocyte, and the thin layer of follicle cells surrounding the nurse cell cluster. The insertion $p n t^{r M 254}(D)$ marks the posterior terminal follicle cells. The line AN277 (E) marks the anterior and posterior polar follicle cells, which appear as two dots of staining, one at the interface between nurse cells and oocyte, and one at the extreme posterior pole. Polar follicle cells are a subset of the terminal follicle cells that lie at the same position. For $A-E$ anterior is to the left and dorsal is up. both embryonic and imaginal disc development (DiazBenjumea and García-Bellido 1990; Raz et al. 1991; Clifford and Schüpbach 1992). Several potential ligands for Egfr have been identified on the basis of their homology to known ligands of the EGF receptor in vertebrates, and it is thought that these ligand molecules act, either singly or in combination, to activate the receptor in its various functions throughout development (Rutledge et al. 1992; Neuman-Silberberg and Schüpbach 1993; Schweitzer et al. 1995a,b). During oogenesis, Egfr appears to be activated by the gurken (grk) gene product, which is a member of the TGF $\alpha$ family of secreted growth factors (Neuman-Silberberg and Schüpbach 1993).

The best characterized function of Egfr signaling in oogenesis is its role in the specification of the dorsalventral pattern of the egg chamber and embryo. Females mutant for grk or certain alleles of Egfr lay ventralized eggs that show an expansion of ventral pattern elements at the expense of dorsal pattern elements (Schüpbach 1987). Although both grk and Egfr produce the same mutant phenotype in oogenesis, the genes are required in different cell types: grk is required in the germ line, whereas Egfr is required in the soma (Schüpbach 1987). This tissue specificity corresponds well with the expression patterns of the two genes: Egfr is expressed in the somatic follicle cells (Kammermeyer and Wadsworth 1987), and grk is expressed in the germ line (NeumanSilberberg and Schüpbach 1993|. The grk mRNA is specifically localized within the germ-line cells throughout oogenesis. In early stages, it accumulates along the posterior cortex of the oocyte, and this localization is maintained until mid-oogenesis, when movement of the oocyte nucleus defines the dorsal-ventral axis. Then, the grk mRNA transiently localizes to the anterior cortex and becomes restricted to the presumptive dorsal-anterior corner in close proximity with the oocyte nucleus (Fig. 1; Neuman-Silberberg and Schüpbach 1993). The asymmetrically localized grk mRNA in the oocyte serves as a localized source of grk protein that presumably activates Egfr in the follicle cells on the dorsal side (Roth et al. 1995).

Although grk and Egfr are the two central components of this signaling system, a number of other genes are involved in the dorsal-ventral patterning process (Table 1). Mutations in the germ-line-required gene cornichon (cni) produce an ovarian phenotype identical to that of $g r k$ and Egfr, and, in addition, strong alleles produce defects in imaginal disc patterning that are also observed in certain allelic combinations of Egfr (Roth et al. 1995). Thus, cni appears to play a more general role in the Egfr signaling pathway. Consistent with the germ-line requirement for the gene, cni is uniformly expressed in germ-line cells during early oogenesis, and it encodes a small, hydrophobic protein that shows no homology with previously characterized proteins. While the germline requirement and ventralized phenotype of cni suggest a role in the production of the grk ligand, analysis of grk mRNA and protein expression in cni mutant ovaries indicates that the gene is not required for transcription, 
Table 1. Genes involved in signaling events during oogenesis

\begin{tabular}{|c|c|c|c|c|}
\hline Gene name & $\begin{array}{l}\text { Ovarian } \\
\text { requirement }\end{array}$ & Phenotype & Homology & Function \\
\hline \multicolumn{5}{|l|}{ EGFR system } \\
\hline $\begin{array}{l}\text { Epidermal growth } \\
\text { factor receptor (Egfr) }\end{array}$ & S & A/P pol;V:Egg/Emb & EGF receptor & $\mathrm{G} \rightarrow \mathrm{S}$ signal receptor \\
\hline gurken (grk) & G & A / P pol; V:Egg/Emb & TGF $\alpha$, secreted growth factor & $\mathrm{G} \rightarrow \mathrm{S}$ signal \\
\hline cornichon (cni) & G & A/P pol, V:Eff / Emb & novel & $?$ \\
\hline$f s(1) K 10\langle K 10|$ & G & $\mathrm{D}: \mathrm{Egg} / \mathrm{Emb}$ & helix-turn-helix motif & grk RNA localization \\
\hline squid (sqd) & $\mathrm{G}(\mathrm{S})$ & $\mathrm{D}: \mathrm{Egg} / \mathrm{Emb}$ & hnRNP A/B & grk RNA localization \\
\hline orb & $G(S)$ & D:Egg/Emb; Post:Emb & RRM RNA-binding proteins & grk, osk RNA localization \\
\hline cappuccino (capu) & G & $\mathrm{D}: \mathrm{Egg} / \mathrm{Emb}$; Post:Emb & formins; diaphanous & grk, osk RNA localization \\
\hline spire [spir) & G & D:Egg/Emb; Post:Emb & N.D. & grk, osk RNA localization \\
\hline Gap & $\mathrm{G} / \mathrm{S}$ & G:Term; S:V:Egg/Emb & GTPase Activating Protein & Egfr signal transduction \\
\hline Raf & $\mathrm{G} / \mathrm{S}$ & G:Term; S:V:Egg & Raf kinase & Egfr signal transduction \\
\hline Mek & $\mathrm{G} / \mathrm{S}$ & G:Term; S:V:Egg & Mapkinasekinase & Egfr signal transduction \\
\hline rhomboid (rho) & S & $\mathrm{V}: \mathrm{Egg} / \mathrm{Emb}$ ? & novel 7-transmembrane protein & Egfr signal modulator? \\
\hline \multicolumn{5}{|l|}{ Notch system } \\
\hline $\operatorname{Notch}(N)$ & (G)S & G:Neu; S:FC pat,A/P pol & EGF repeats; receptor & FC signaling receptor \\
\hline $\operatorname{Delta}(D I)$ & (G)S & G:Neu; S:FC pat,A / P pol & EGF repeats; ligand & FC ligand for $N$ \\
\hline big brain $\mid$ bib $\mid$ & $(\mathrm{G}) \mathrm{S}$ & $\mathrm{G}: \mathrm{Neu}_{;} \mathrm{S} ?$ & & $N$ signal transduction? \\
\hline neuralized (neur) & (G)S & $\mathrm{G}: \mathrm{Neu}_{;} \mathrm{S} ?$ & novel & $N$ signal transduction? \\
\hline daughterless $($ da $)$ & (G)S & G:SexDet:Emb; S:FC pat & bHLH transcription factor & $?$ \\
\hline brainiac $(b r n)$ & $\mathrm{G}$ & $\mathrm{Neu} \mathrm{V}: \mathrm{Egg} / \mathrm{Emb}$ & N.D. & Egfr/ $N$ receptor modulation? \\
\hline \multicolumn{5}{|c|}{ Other signaling systems in the ovary } \\
\hline dicephalic (dic) & G & O pos & N.D. & $\mathrm{A} / \mathrm{P}$ axis orientation? \\
\hline spindle-C $(\operatorname{spn} C)$ & G & O pos & N.D. & $\mathrm{A} / \mathrm{P}$ axis orientation? \\
\hline protein kinase $A(P K A)$ & G & A/P pol & protein kinase $\mathrm{A}$ & $S \rightarrow G$ signal transduction \\
\hline \multicolumn{5}{|l|}{ Terminal system } \\
\hline torsolike (tsl) & $S$ & Term & novel, secreted? & terminal somatic signal \\
\hline torso (tor) & G & Term & receptor tyrosine kinase & terminal system receptor \\
\hline trunk $\{$ trk $\mid$ & G & Term & Cys-rich growth factor? & tor ligand? \\
\hline$f_{s}(1)$ Nasrat $\left[f_{s}(1 \mid N]\right.$ & G & Term & N.D. & \\
\hline$f s(1 \mid$ polehole $[f s|1| p h]$ & G & Term & N.D. & \\
\hline Ras pathway & $\mathrm{G}$ & Term & Sos, Ras, Raf, Mek, rl, etc. & tor signal transduction \\
\hline geneY & $|G|$ & - & - & Term determinant? \\
\hline \multicolumn{5}{|l|}{ Dorsal-ventral system } \\
\hline windbeutel (wind) & $\mathrm{s}$ & D:Emb & N.D. & $\mathrm{D} / \mathrm{V}$ somatic signal? \\
\hline nudel (nud) & S & $\mathrm{D}: \mathrm{Emb}$ & matrix proteins; protease & $\mathrm{D} / \mathrm{V}$ somatic signal? \\
\hline pipe (pip) & S & $\mathrm{D}: \mathrm{Emb}$ & N.D. & $\mathrm{D} / \mathrm{V}$ somatic signal? \\
\hline gastrulation defective ( $g d$ ) & G & D:Emb & serine protease & protease cascade \\
\hline snake (snk) & G & D:Emb & serine protease & protease cascade \\
\hline easter $(e a)$ & G & D:Emb & serine protease & $s p z$ activation \\
\hline spätzle (spz) & G & D:Emb & Cys-rich growth factor? & $T l$ ligand \\
\hline Toll $(T 1)$ & $\mathrm{G}$ & $\mathrm{D}: \mathrm{Emb}$ & IL-1 receptor & $\mathrm{D} / \mathrm{V}$ signal receptor \\
\hline tube $(t u b)$ & G & $\mathrm{D}: \mathrm{Emb}$ & novel & $T 1$ signal transduction \\
\hline pelle (pll) & G & $\mathrm{D}: \mathrm{Emb}$ & Ser-Thr kinase & $T 1$ signal transduction \\
\hline cactus (cact) & $\mathrm{G}$ & $\mathrm{V}: \mathrm{Emb}$ & IкB & $d l$ regulation \\
\hline dorsal (dl) & G & D:Emb & $\mathrm{NF}-\mathrm{kB}$, transcription factor & $\mathrm{D} / \mathrm{V}$ determinant \\
\hline \multicolumn{5}{|l|}{ Anterior and posterior systems } \\
\hline bicoid $(b c d)$ & G & Ant:Emb & homeo box transcription factor & Ant determinant \\
\hline oskar (osk) & G & Post:Emb & novel & pole plasm assembly \\
\hline nanos (nos) & G & Post:Emb & novel & post determinant \\
\hline
\end{tabular}

Abbreviations: (G) Germ line; (S) soma; [(G) or $(S)]$ requirements not directly involved in ovarian signaling events; (A/P pol) anterior posterior polarity of oocyte (bcd, osk, kinßgal localization); (V) ventralization; (D) dorsalization; (Egg) of eggshell; (Emb) of embryo; (Post) posterior defects in embryo (posterior group phenotype); (Term) terminal defects in embryo (terminal group phenotype); (Ant) anterior defects in embryo (anterior group phenotype); (Neu) neurogenic phenotype; (FC pat) follicle cell patterning defects; (SexDet) embryonic sex determination; (O pos) positioning of oocyte in germline cluster.

References: (Egfr, grk, cni) Livneh et al. (1985); Neumann-Silberberg and Schüpbach (1993); Roth et al. (1995). (K10) Wieschaus et al. (1978); Wieschaus (1979); Prost et al. (1988). (sqd) Kelley (1993). (orb) Lantz et al. (1994); Christerson and McKearin (1994). (capu, spir) Manseau and Schüpbach (1989); Emmons et al. (1995). (Gap) Gaul et al. (1992). (Raf) Brand and Perrimon (1994). (Mek) Hsu and Perrimon (1994). (rho) Ruohola-Baker et al. (1993). (N, Dl, bib, neur) Ruohola et al. (1991). (da) Cummings and Cronmiller (1994). (brn) Goode et al. (1992). (dic) Frey et al. (1984). (spnC) Gonzáles-Reyes and St. Johnston (1994). (PKA) Lane and Kalderon (1994). (tsl) Savant-Bhonsale and Montell (1993). (trk) Casanova et al. (1995). [tor, fs(1)N, fs(1)ph, Ras pathway, geneY] reviewed in Lu et al. (1993). (nud) Hong and Hashimoto (1995). (wind, pip, gd, snk, ea, spz, Tl, tub, pll, cact, dl) reviewed in Morisato and Anderson (1995). (bcd) reviewed in St. Johnston and Nüsslein-Volhard (1992). (osk, nos) reviewed in Rongo and Lehmann (1996). 
localization, or translation of grk mRNA. However, grk protein is more diffuse in the mutant egg chambers, suggesting that cni may be involved in secretion, localization, or perhaps activation of grk protein (Roth et al. 1995).

A group of five germ-line-required genes, $f_{s}(1) K 10$ (K1O), squid (sqd), orb, cappuccino (capu), and spire (spir) have been identified that are involved in the localization of grk mRNA to the periphery of the oocyte nucleus. In the mutant egg chambers, grk mRNA does not localize to the dorsal-anterior corner of the oocyte, but rather is localized in a ring at the anterior cortex (Neuman-Silberberg and Schüpbach 1993; Christerson and McKearin 1994; Roth and Schüpbach 1994). The $K 10$ and sqd genes appear to be specifically involved in dorsal-ventral patterning, and the mutant females lay dorsalized eggs in which dorsal follicle cell fates are expanded at the expense of ventral fates (Wieschaus et al. 1978; Wieschaus 1979; Kelley 1993). K10 encodes a novel protein that contains a small domain with homology to a prokaryotic helix-turn-helix motif, suggesting that the gene product may be a nucleic acid-binding protein (Prost et al. 1988). The sqd locus encodes several isoforms of a heterogeneous nuclear ribonucleoprotein, hrp 40 , that is similar to the hnRNP A/B proteins of vertebrates, suggesting a role for sqd in grk RNA metabolism (Kelley 1993). Both $K 10$ and $s q d$ proteins are localized to the oocyte nucleus after it has moved to the future dorsal-anterior corner in mid-oogenesis (Prost et al. 1988; Matunis et al. 1994). Although this subcellular localization is intriguing in light of the homologies of the two genes to nuclear proteins, it has yet to be shown whether the localization is essential for the function of either product.

Mutations in orb, capu, and spir have more general effects on RNA localization in the ovary, and the phenotypes produced by the mutants are more variable. Females mutant for maternal effect alleles of orb lay lateralized or ventralized eggs (Christerson and McKearin 1994; Lantz et al. 1994; Roth and Schüpbach 1994), and the grk mRNA, while localized to the anterior of the oocyte, is not confined to the cortex (as in K10 and sqd) but is spread into central regions of the ooplasm (Roth and Schüpbach 1994). In addition to this defect, orb mutants affect the posterior localization of oskar (osk) mRNA and other components of the pole plasm (Christerson and McKearin 1994; Lantz et al. 1994). The orb gene encodes a protein with similarity to the RNA recognition motif (RRM) family of RNA or singlestranded nucleic acid-binding proteins (Lantz et al. 1992), and thus the gene product may interact directly with grk and osk RNAs in the oocyte. A similar phenotype is produced by the recently characterized gene homeless (hls) (Gillespie and Berg 1995). Mutations in hls also produce ventralized eggshells and affect the localization of RNAs, in particular bcd and osk, in the oocyte. hls encodes a protein with homology to the DE-H family of RNA-dependent ATPases, and thus, like orb, may be interacting with RNAs in the oocyte. Females mutant for capu and spir lay predominantly dorsalized eggs, like $K 10$ and sqd, but the phenotype is vari- able, and ventralized eggs are also observed (Manseau and Schüpbach 1989; Emmons et al. 1995). Like orb, capu and spir affect localization of grk mRNA, as well as components of the posterior pole plasm (Manseau and Schüpbach 1989). In addition, the mutant egg chambers show abnormal distributions of microtubules and are defective in a number of microtubule-based processes in the oocyte (Emmons et al. 1995). Thus, these genes may affect RNA localization by regulating microtubule dynamics. Molecular characterization of capu provides some support for this model. The carboxyl terminus of the predicted capu protein shows homology to vertebrate formins, including the limb deformity locus in mouse, the BNI1 gene of Saccharomyces cerevisiae, the CDC12 and fus1 genes of Schizosaccharomyces pombe, the FigA gene of Aspergillus, and the diaphanous gene of Drosophila (Emmons et al. 1995). Although these proteins are involved in a wide variety of different processes, a number of them do affect cytoskeletal rearrangements, though in the cases of CDC12 and fus1, the proteins appear to interact with the actin rather than the microtubule cytoskeleton (Chang and Nurse 1996; Chang et al. 1996).

Most of the known genes required for transmission of the Egfr signal in the somatic follicle cells are Drosophila homologs of components of the vertebrate Ras pathway. For the most part, these genes have not been identified by their effects on patterning during oogenesis because they are involved in essential processes earlier in development. However, through the use of genetic and molecular techniques, a number of the genes have been implicated in Egfr signaling in oogenesis. For instance, the Drosophila homolog of the GTPase activating protein (GAP) appears to antagonize Egfr signaling in the follicle cells. Females mutant for amorphic alleles of Gap lay weakly dorsalized eggs (Gaul et al. 1992), which is consistent with ectopic activation of the Egfr pathway, and analysis of this phenotype in mosaic females indicates that Gap is required in the soma for dorsal-ventral patterning (Chou et al. 1993). Notably, because GAP1 is known to interact directly with Ras (Bourne et al. 1990), this result also implicates Drosophila Ras in the pathway. Two other Ras pathway genes, Raf and Mek, have been shown to play a positive role in dorsal-ventral patterning in the follicle cells. Certain loss-of-function alleles of Raf cause weak ventralization of the chorion, while a synthetic dominant activated $R$ af allele can dorsalize the eggshell when expressed in the follicle cell epithelium (Brand and Perrimon 1994). A synthetic temperature-sensitive allele of Drosophila Mek also ventralizes the chorion when females are shifted to the restrictive temperature (Hsu and Perrimon 1994). The fact that genes at the beginning (Gap), middle (Raf), and end (Mek) of the Ras pathway appear to play a role in dorsal-ventral patterning in the ovary suggests strongly that the entire pathway is acting downstream of Egfr in the follicle cells.

The rhomboid (rho) gene is also required in the soma for Egfr signaling. rho, which was identified initially on the basis of its role in embryonic patterning, encodes a 
novel trans-membrane protein that is involved in Egfr signaling processes at all stages of the life cycle (Bier et al. 1990; Ruohola-Baker et al. 1993; Sturtevant et al. 1993). As a result of these requirements earlier in development, tho function in the ovary was deduced largely from its expression pattern and the phenotypes produced by ectopic expression of sense and antisense RNAs. In the ovary, rho is first expressed in mid-oogenesis, when the oocyte nucleus has moved to the dorsal-anterior corner. At this time, the gene is expressed in a ring of follicle cells that lie at the junction between the nurse cells and oocyte (Fig. 1), and in a patch of dorsal follicle cells that lie over the oocyte nucleus (Ruohola-Baker et al. 1993). Studies on rho expression in mutant ovaries indicate that the dorsally restricted aspect of this pattern depends on Egfr signaling. In grk mutant egg chambers, rho is not expressed in the dorsal follicle cells, whereas in $K 10$ mutant egg chambers, the dorsal patch is expanded to form a broad band around the circumference of the egg chamber (Ruohola-Baker et al. 1993; NeumanSilberberg and Schüpbach 1994). In addition, expression of rho antisense RNA in the follicle cell epithelium causes a ventralization of the eggshell, indicating that, like Egfr, rho is required for the specification of dorsal follicle cell fates (Ruohola-Baker et al. 1993). These results are consistent with the idea that rho is a downstream target of Egfr. Ectopic expression of rho sense RNA causes a dorsalization of the eggshell, implying that, at some level, rho can activate the Egfr pathway in the soma. However, Egfr activation by rho is grk dependent, indicating that although rho may modulate receptor function, it cannot activate the receptor independent of the ligand (Ruohola-Baker et al. 1993). Taken together, these facts have led to a model in which rho is a target of Egfr in the follicle cells that acts to modulate or enhance the signal and produce an effective high point of Egfr activity in the dorsal follicle cells. It has been suggested that because rho encodes a membrane protein, it may interact directly with Egfr in the plasma membrane to regulate receptor activity (Sturtevant et al. 1993).

\section{The torpedo/DER signaling system and anterior- posterior patterning}

Prior to its requirement for dorsal-ventral patterning, the Egfr signaling pathway is involved in anterior-posterior patterning of the follicle cell epithelium and polarization of the anterior-posterior axis of the oocyte. The defect in anterior-posterior follicle cell patterning is evident in the morphology of the mutant eggs. The wildtype chorion has distinct anterior and posterior ends: There is a micropyle at the anterior pole and an aeropyle at the posterior pole. In grk, Egfr, and cni eggs, there is frequently a second micropyle at the posterior pole (Gonzáles-Reyes et al. 1995; Roth et al. 1995). This duplication of anterior structures at the posterior is also evident during oogenesis. In wild-type egg chambers, the micropyle is secreted by two anterior follicle cell types: border cells and centripetal follicle cells (Fig. 1). In grk, Egfr, and cni mutant ovaries, molecular markers specific for these cell types are duplicated at the posterior pole, indicating that in the mutant egg chambers, the presumptive posterior follicle cells take on an anterior fate, resulting in the secretion of a second micropyle at the posterior (Gonzáles-Reyes et al. 1995; Roth et al. 1995). Thus, Egfr signaling is required to specify posterior follicle cell fates, and in the absence of this signal, the posterior terminal follicle cells adopt anterior fates.

The effect of Egfr signaling on the anterior-posterior polarity in the germ line is evident from the localization of cytoplasmic determinants in the oocyte. In egg chambers mutant for grk, Egfr, or cni, bcd mRNA, which is normally localized in a ring at the anterior cortex, is localized to both the anterior and posterior poles, and osk mRNA, which is normally localized to the posterior pole, is displaced to the middle (Gonzáles-Reyes et al. 1995; Roth et al. 1995). This change in RNA localization in the oocyte appears to result from a defect in the organization of the microtubule cytoskeleton in the mutant egg chambers. In early stage wild-type egg chambers, microtubules in the germ-line are polarized with their minus ends in a microtubule organizing center (MTOC)like structure at the posterior pole of the oocyte and their plus ends extending through the cytoplasmic bridges into the nurse cells. In mid-oogenesis, this polarity is reversed: the MTOC at the posterior breaks down, and microtubules begin to accumulate at the anterior cortex in a gradient to the posterior (Theurkauf et al. 1992). The polarity of the microtubules at this stage can be monitored by a kinesin- $\beta$-galactosidase (kin:ßgal) fusion protein that accumulates at the plus ends of microtubules (Clark et al. 1994). In wild-type egg chambers, kin:ßgal localizes to the posterior pole after the microtubule reorganization while in $g r k, E g f r$, and cni mutant egg chambers, it accumulates in the middle, like the osk mRNA (Gonzáles-Reyes et al. 1995; Roth et al. 1995). This indicates that, in the mutant egg chambers, the microtubule network in the oocyte has a symmetrical organization with minus ends at both poles and plus ends directed toward the center. Thus, Egfr signaling is required not only to specify posterior follicle cell fates, but also to establish the anterior-posterior polarity of the microtubules in the oocyte.

Because Egfr is required only in the soma, the observation that mutations in the gene affect both follicle cell patterning and oocyte polarity indicates that activation of the Egfr system in the follicle cells must lead to the production of a second signal back to the oocyte that mediates the effect on microtubule polarity. Thus, the correct specification of anterior-posterior polarity in the egg chamber depends on bidirectional signaling from the oocyte to the follicle cells and then back to the oocyte (Ruohola et al. 1991; Gonzáles-Reyes and St. Johnston 1994; Gonzáles-Reyes et al. 1995; Roth et al. 1995). Although currently uncharacterized, the second signal from the posterior follicle cells back to oocyte appears to involve the Drosophila cAMP-dependent protein kinase $A(P K A)$ gene. In egg chambers mutant for $P K A, b c d$ and osk mRNAs as well as the kin:ßgal fusion protein are mislocalized as they are in the grk, Egfr, and cni mutant 
ovaries: bcd is localized to both anterior and posterior poles, and osk and kin:ßgal are displaced to the middle (Lane and Kalderon 1994). As the same phenotypes are observed in germ-line clones, these data suggest that $P K A$ is a germ-line-required target of the soma to germline signal that is produced by the posterior follicle cells.

\section{Dorsal-ventral patterning depends on anterior- posterior polarity}

The defect in the organization of the microtubule network in the grk, Egfr, and cni mutant ovaries also affects the movement of the oocyte nucleus to an anterior corner, and consequently, the subsequent Egfr-dependent dorsal-ventral patterning process. In wild type, the movement of the oocyte nucleus, which defines the dorsal-ventral axis, occurs at the same time as the cytoskeleton is reorganized, and this movement appears to be microtubule dependent (Koch and Spitzer 1983; Gutzeit 1986). Consistent with a role for microtubules in the process, it has been shown that Drosophila cytoplasmic dynein, a minus-end-directed motor, accumulates at the periphery of the oocyte nucleus at this time ( $\mathrm{Li}$ et al. 1994). Because the oocyte nucleus normally moves toward the minus ends of microtubules, that is, anteriorly, and because grk, Egfr, and cni mutant egg chambers have minus ends of microtubules at both poles, in the mutant egg chambers, the oocyte nucleus could potentially move to either pole. This is, in fact, what is observed. In the mutants, the oocyte nucleus occasionally moves to the anterior, as in wild type, but more frequently remains at the posterior pole, and in some cases lies between the two poles (Gonzáles-Reyes et al. 1995; Roth et al. 1995). These data indicate that normal microtubule polarity in the oocyte is required for the anterior movement of the oocyte nucleus and the establishment of dorsal-ventral asymmetry in the egg chamber. Thus, the polarization of the dorsal-ventral axis depends on the earlier polarization of the anterior-posterior axis.

This dependence of the dorsal-ventral polarity on the polarization of the anterior-posterior axis suggests a model in which the dorsal-ventral asymmetry in the oocyte is defined by a stochastic movement of the oocyte nucleus. As discussed above, after the reorganization, the microtubules form an anterior to posterior gradient that is confined to the oocyte cortex. Given that the oocyte nucleus moves along these microtubules, and, as there are no microtubules running down the middle of the ooplasm, a simple anterior movement would require that the nucleus choose a direction to follow the microtubules along the cortex. Inevitably, this would lead to the asymmetric placement of the oocyte nucleus in the anterior cortex. It is plausible that this choice is the random element in the process and that slight stochastic differences in the microtubule network create a bias toward one side that results in the nucleus moving in one direction versus another. In this way, the asymmetric placement of the nucleus is a consequence of this anterior movement in the oocyte, which depends on the prior polarization of the anterior-posterior axis.

\section{Notch signaling and follicle cell patterning}

The observation that Egfr signaling events mediate first anterior-posterior and subsequently dorsal-ventral patterning in the egg chamber raises the question of how the former signal is distinguished from the latter: In both cases, signaling is from the oocyte to the adjacent follicle cell epithelium, and yet two completely different responses are produced. This distinction is achieved, at least in part, by a restriction on the cells that are competent to respond to the first (anterior-posterior) signaling event. This restriction is apparent in the phenotypes observed in egg chambers mutant for the genes, $d i$ cephalic (dic), spindle C (spnC), and armadillo, that affect the placement of the oocyte at the posterior of the germ-line cluster (Frey et al. 1984; Peifer et al. 1993; Gonzáles-Reyes and St. Johnston 1994). In these mutants, egg chambers often develop with the oocyte in the middle and nurse cells flanking it both anteriorly and posteriorly. In such bipolar egg chambers, the oocyte is not in contact with the follicle cells at the posterior end of the chamber, and thus they cannot receive the signal from the oocyte. As a consequence, the posterior terminal follicle cells take on anterior fates, as in the grk, Egfr, and cni mutants, and the resulting eggs have micropyles at both poles (Gonzáles-Reyes and St. Johnston 1994). Significantly, the main body follicle cells that are adjacent to the oocyte, and could potentially receive the signal from the oocyte, do not adopt the posterior follicle cell fate and do not signal back to the oocyte to reorganize the cytoskeleton (Gonzáles-Reyes and St. Johnston 1994). These observations indicate that only terminal follicle cells are competent to receive and respond to the Egfr-mediated signal from the oocyte. Therefore, a prerequisite for the anterior-posterior patterning process mediated by Egfr is the proper specification of terminal and main body cells in the follicular epithelium. This process appears to depend on intercellular signaling events in the follicle cells that are mediated by the Notch signaling system.

The Notch signaling pathway is a widely conserved intercellular communication system that plays a central role in cell fate specification via local cell-cell interactions (for review, see Artavanis-Tsakonas et al. 1995). The receptor, $N$, is a large trans-membrane protein with an extracellular domain containing a tandem array of 36 EGF-like repeats (Wharton et al. 1985; Kidd et al. 1986) and a cytoplasmic domain containing six tandem ankyrin repeats that mediate interactions between the receptor and other proteins (Diederich et al. 1994; Fortini and Artavanis-Tsakonas 1994). Two genes, Delta (DI) and Serrate (Ser), have been identified as ligands for $N$ (Fehon et al. 1990; Rebay et al. 1991), and these encode membrane-anchored, extracellular proteins. Like $N$, the $\mathrm{Dl}$ and Ser proteins contain tandem arrays of EGFlike repeats (Vässin et al. 1985; Kopczynski et al. 1988; Fleming et al. 1990; Thomas et al. 1991). Of the two potential ligands, $D l$ is more generally used, and appears to be the ligand for $N$ during oogenesis (Ruohola et al. 1991). 
In the ovary, mutant phenotypes associated with $N$ and $D l$ were analyzed with conditional alleles that could bypass requirements for the two genes earlier in development. When shifted to the nonpermissive temperature, females bearing these alleles become sterile and exhibit defects in the specification of terminal follicle cell fates and in oocyte polarity (Ruohola et al. 1991). In the wildtype germarium, egg chambers are formed by the interleaving of follicle cells between adjacent germ-line clusters, and subsequently, a small population of specialized follicle cells, called stalk cells, form a narrow stem between adjacent chambers. In germaria mutant for $N$ and $D l$, both of these processes are defective: Follicle cells do not properly interleaf between adjacent clusters, and stalk cells are morphologically abnormal and fail to form a stalk. Egg chambers that had already pinched off from the germarium before the temperature shift develop normally until mid-oogenesis, at which point defects are evident both in the follicle cell epithelium and in the oocyte. In wild-type egg chambers, terminal follicle cell clusters include a specialized pair of follicle cells, called polar follicle cells (Fig. 1), that can be distinguished from other terminal follicle cells on the basis of the expression of specific markers such as Fasciclin III (Ruohola et al. 1991). In the mutant egg chambers, there are more cells expressing these markers at the posterior pole of midstage egg chambers. In the mutant oocytes, $b c d$ mRNA is localized to both the anterior and posterior poles, and osk mRNA is displaced to the middle. Thus, $N$ and $D I$ have the same effect on oocyte polarity as grk, Egfr, cni, and PKA. As mosaic females mutant for $N$ and $D I$ in the germ line but not in the soma show no defects in oogenesis, all of these mutant phenotypes, including the oocyte polarity defect, are associated with loss of $N$ and $D l$ function in the somatic cells. Thus, Notch signaling in oogenesis appears to directly regulate the specification of different populations of follicle cells within the follicular epithelium, and indirectly control the anterior-posterior polarity of the oocyte.

Studies on $N$ signaling in a number of different tissues have led to the idea that the Notch system acts to sort different cell types from an initially uniform population by local inhibitory cell-cell interactions-a process that has been referred to as lateral inhibition (for review, see Artavanis-Tsakonas et al. 1995). Consistent with a generalized role for $N$ in cell fate decisions, these studies also indicate that the system often acts in several consecutive sorting events within the same cell lineage. For instance, during the development of adult sensilla, $N$ and Dl have two consecutive functions, first to sort sensillum precursors from epidermal precursors, and then to sort the sensillum precursors into sensory neurons and accessory cells (Hartenstein and Posakony 1990; Parks and Muskavitch 1993). The role of $N$ in follicle cell patterning might be similarly modeled. The temperature shift experiments define two temporally distinct $N$ requirements in oogenesis: an early requirement in the germarium for specification of terminal follicle cells and stalk cells, and a later one in the vitellarium for the specification of polar follicle cells. Thus, the Notch sys- tem may function in the germarium to sort main body follicle cells, terminal follicle cells, and stalk cells, and then, in the vitellarium to sort terminal follicle cells and polar follicle cells. With this in mind, it is tempting to speculate that the observed defects in oocyte polarity may be an indirect consequence of the failure to establish a distinction between terminal and polar follicle cells. The polar cell hyperplasia, observed at the posterior end of $N$ and $D l$ mutant egg chambers may interfere with the reception of or response to the Egfr-mediated signal from the germ line, and thus indirectly disrupt the bi-directional signaling required to establish the anterior-posterior polarity of the oocyte.

In addition to $N$ and $D l$, cell fate specification in the follicle cell epithelium requires other genes that are known to be involved in Notch signaling events in other tissues (Table 1). For instance, two neurogenic genes, big brain (bib) and neuralized (neur) are expressed during oogenesis, and their expression patterns are consistent with the idea that Notch signaling is involved in terminal follicle cell patterning (Ruohola et al. 1991). Both genes are generally expressed in follicle cells in the germarium, and in later stages neur is expressed exclusively in anterior and posterior polar follicle cells, whereas bib is restricted to posterior terminal follicle cells. By phenotypic criteria, the daughterless $(d a)$ gene, which encodes a widely expressed bHLH transcription factor, is also involved in terminal follicle cell specification (Cummings and Cronmiller 1994). Studies on a weak hypomorphic $d a$ allele revealed defects in oogenesis, including loss of stalk cells and egg chamber fusions, that are similar to those produced by the $N$ and $D l$ mutations. Furthermore, genetic studies indicate that $d a$ shows dominant synergistic interactions with $N$ and $D I$, and with the neurogenic gene mastermind /Cummings and Cronmiller 1994|, suggesting that all of these genes are involved in the same pathway controlling follicle cell specification.

The neurogenic gene brainiac (brn) is unique in that it appears to affect functions mediated by both the Egfr and the Notch signaling systems (Goode et al. 1992). brn function is required in the germ-line during oogenesis and appears to have two functions. Similar to the neurogenic genes, brn is required for embryonic neurogenesis, and eggs produced by mutant mothers show hypertrophy of the embryonic central nervous system. However, unlike the neurogenic genes, brn is also required for dorsal-ventral patterning of the egg chamber: eggs laid by the mutant females are weakly ventralized like those produced by hypomorphic alleles of grk and Egfr. Furthermore, brn exhibits genetic interactions with Egfr, suggesting that the gene may be directly involved with Egfr signaling in dorsal-ventral patterning. Further characterization of the gene will be required to determine its role in these signaling pathways.

\section{Establishment of anterior-posterior polarity}

Although the early Egfr signaling process is clearly the crucial step in establishing anterior-posterior and dor- 
sal-ventral polarity, the event is not the origin of polarity in oogenesis. The constraints on the process, in particular, the restriction of cells that are competent to respond to the signal, suggest that prior events are required to regulate the process. Three largely independent events, one occurring in germ-line, one in the soma, and one involving communication between germ-line and soma, are prerequisites for later Egfr signaling. First, in the germ line, determination of the oocyte leads to the early localization of $g r k$ mRNA to it, and this event serves to restrict the source of the signal to a small region of the egg chamber. Second, in the soma, Notch signaling distinguishes main body and terminal follicle cell fates, as described above, and this establishes the cell type that is competent to respond to the signal. Finally, the posterior positioning of the oocyte within the germline cluster results in the juxtaposition of the oocyte (the source of the signal) with the terminal follicle cells (the target of the signal).

The posterior positioning of the oocyte within the germ-line cluster, which initially defines the anteriorposterior polarity, must also involve intercellular communication. Because the movement of the oocyte is directed both toward the posterior of the ovariole and specifically toward terminal follicle cells, at some level, communication between follicle cells and oocyte is required to mediate the process. On the simplest level, a signal from posterior terminal follicle cells to the oocyte would serve to direct the movement of the oocyte and thus result in the proper juxtaposition of oocyte and follicle cells. The process might involve ligand-receptor interaction or simply reflect different adhesive properties of the oocyte and follicle cells that mediate their association. Notably, two genes that might be involved in this signaling process are spnC and dic, which affect the positioning of the oocyte in the germ-line cluster. Molecular characterization of these genes may provide the first hints about how the movement is regulated.

\section{From ovary to embryo}

Although the combination of Egfr-and Notch-dependent signaling events leads to the establishment of anteriorposterior and dorsal-ventral polarity in the egg chamber, the problem of how these events in oogenesis lead to the asymmetric localization or local activation of determinants in the embryo still remains. Along the anteriorposterior axis, the localization of $b c d$ and nos mRNAs to the anterior and posterior poles, respectively, is a direct consequence of the reorganization of the microtubule network in mid-oogenesis: $b c d$ mRNA accumulates at the anterior cortex of the oocyte, where it remains until it is translated during embryogenesis (St. Johnston et al. 1989), and osk mRNA is transported to the posterior pole, where it directs the stepwise assembly of the germ plasm, eventually incorporating the nos mRNA (Rongo and Lehmann 1996). The localization of these RNAs is microtubule dependent (Pokrywka and Stevenson 1991; Clark et al. 1994), implicating minus-end-directed motors in the localization of $b c d$ and plus-end-directed mo- tors in the localization of osk and nos. In addition, genetic studies indicate that osk localization requires Drosophila cytoplasmic tropomyosin, suggesting that the actin cytoskeleton is involved in the transport process as well (Erdélyi et al. 1995).

The localized activation of the tor RTK, which directs patterning of the terminal segments of the embryo, involves a delayed intercellular signaling event between the follicle cells during oogenesis and the embryo after fertilization. The restricted activation of the receptor is achieved, at least in part, by the localized expression of an upstream gene, torsolike (tsl), that is required in the somatic follicle cells during oogenesis (Stevens et al. 1990; Savant-Bhonsale and Montell 1993). The tsl gene is expressed in the anterior and posterior terminal follicle cells, which will secrete the micropyle and aeropyle, and this pattern is consistent with tsl functioning to restrict tor activation to the polar regions. The gene encodes a novel protein with an amino-terminal signal sequence, suggesting that it is secreted (Savant-Bhonsale and Montell 1993). Because of the delay between the time that $t s l$ is expressed in oogenesis and the time that tor is activated in embryogenesis, it has been suggested that the $t s l$ protein is incorporated into the vitelline membrane where it is stably maintained until fertilization when the downstream elements in the pathway are activated ( $\mathrm{Sa}$ vant-Bhonsale and Montell 1993).

In addition to tor and $t s l$, four other maternal genes have been identified that are required for terminal patterning: $f_{S}(1)$ Nasrat $\left[f_{S}(1) N\right]$, trunk $(t r k), f_{s}(1)$ polehole [fs(1)ph], and l(1)polehole [1(1)ph] (Table 1). These genes are all germ-line dependent, and epistasis experiments with gain-of-function tor alleles indicate that $f_{s}(1) N$, $f_{s}(1) p h$, and trk function upstream of the receptor, whereas 1(1)ph functions downstream (for review, see $\mathrm{Lu}$ et al. 1993). These results implicate the former genes in the production of the tor ligand and the latter gene in transduction of the tor signal. The tor ligand appears to be encoded by $t r k$. The predicted trk protein contains an amino-terminal signal sequence, a proteolytic cleavage site with similarity to a portion of the complement component $3(\mathrm{C} 3 \mid$, and a stretch of cysteines suggestive of the cysteine knot motif found in several other growth factors and extracellular ligands (Casanova et al. 1995). These features suggest that trk encodes a secreted precursor protein that requires proteolytic cleavage to produce the active ligand. As $f_{s}(1) N$ and $f_{S}(1) p h$ also act upstream of the receptor, these genes are likely to be involved in transmitting the localized cue from tsl or perhaps in the activation of $t r k$.

Genes that act downstream of tor include I(1)ph, which encodes the Drosophila homolog of Raf (Mark et al. 1987; Nishida et al. 1988), and genetic studies indicate that other components of the Ras pathway, including Sos, Ras, Raf, $M k k$, and $M e k$ are all involved in transduction of the tor signal (Lu et al. 1993). Thus, the same set of genes that transduces the Egfr signals in the follicle cell epithelium during oogenesis are required in the germ line for transduction of the tor signal during embryogenesis. The activation of the Ras pathway by tor leads 
to the differential expression of two genes, tailless (tll) and huckebein $(h k b)$, and it has been proposed that these zygotic genes are regulated by a maternal transcription factor, the postulated geneY, that, once phosphorylated in response to tor, activates transcription from the tll and $h k b$ promoters.

The localized activation of $T 1$, the receptor that directs dorsal-ventral patterning in the embryo, is conceptually similar to that of tor activation in that it requires intercellular communication between the follicle cells and the embryo. Twelve genes have been identified that are involved in this signaling process, the 11 dorsal group genes, windbeutel (wind), nudel (nud), pipe (pip), gastrulation defective $(g d)$, snake (snk), easter (ea), spätzle $(s p z), T l$, tube (tub), pelle (pll), and dorsal (dl), and cactus (cact) (Table 1) (for review, see Morisato and Anderson 1995). Epistasis experiments with dominant gain-offunction alleles of $T l$ demonstrate that wind, nud, pip, $g d, s n k, e a$, and $s p z$ function upstream of the receptor, while the remaining genes function downstream. Furthermore, analysis of mosaic females indicates that three of the genes, wind, nud, and pip, are required in the somatic follicle cells. Null alleles of all of the genes except cact dorsalize the embryo, indicating that the pathway is active on the ventral side of the embryo and is required for the specification of ventral fates. cact, which plays an antagonistic role, produces a ventralized phenotype.

The ventral activation of the $T l$ signaling pathway suggests that the activity of the three somatic dorsal group genes is restricted to ventral follicle cells, where they act to generate a localized cue that is transmitted to the embryo after fertilization. Molecular characterization of nud suggests that it may be a component of this cue. The nud gene encodes a large secreted protein that resembles extracellular matrix proteins and contains a region similar to the catalytic domains of serine proteases of the trypsin family (Hong and Hashimoto 1995). These characteristics suggest that, like tsl, nud is secreted by the follicle cells and possibly incorporated into the vitelline membrane. The presence of the serine protease domain suggests that nud acts as a protease, which is consistent with the functions of the next three genes in the pathway, $g d$, snk, and $e a$, which also encode serine proteases of the trypsin family and are thought to be components of a serine protease cascade in the perivitelline space (for review, see Roth 1994). Thus, localized activation of nud in the vitelline membrane may be the localized cue for the activation of a serine protease cascade in the perivitelline space that leads to the production of the $T I$ ligand.

The ligand for $T l$ appears to be $s p z$. The $s p z$ gene encodes a novel secreted protein that, like $t r k$, contains a carboxy-terminal cysteine-rich region reminiscent of the cysteine knot motif found in many vertebrate growth factors (Morisato and Anderson 1994). Biochemical studies indicate that the nascent $s p z$ protein is proteolytically processed to produce the active ligand, which is consistent with it being regulated by the upstream serine protease cascade. Activation of $T l$ initiates a intracellu- lar signaling cascade in the embryo, involving the tub and pll genes, that leads to the formation of the $d l$ gradient. The $d l$ gene encodes a homolog of the transcription factor NF-кB, while cact is related to $I \kappa B$, and like their vertebrate homologs, $d l$ and cact form a inactive complex in the cytoplasm. Tl signaling disrupts this complex, and leads to translocation of $d l$ into the nucleus, where it acts to regulate transcription of zygotic genes. While the origin of the gradient is not clear, it has been proposed that its shape is already evident in the distribution of active $s p z$, which implies that the downstream genes are simply transmitting this pattern to $d l$ (Roth 1993; Morisato and Anderson 1994).

The ventral activation of $T l$ during embryogenesis depends on the prior dorsal activation of Egfr during oogenesis (Schüpbach 1987). In addition to affecting the dorsal-ventral pattern of the eggshell, as described above, $g r k$, Egfr, and cni mutations also affect the dorsal-ventral pattern of the embryo that develops inside. Like the chorion, the mutant embryos are ventralized (Schüpbach 1987), which indicates that the principle effect of Egfr on embryonic patterning is to restrict the production of active $T l$ ligand to the ventral side. However, there are indications that the pathway from Egfr to $T l$ is not direct. Comparison of the embryonic ventralized phenotype produced by grk, Egfr, and cni mutants with that produced by dominant gain-of-function alleles of dorsal group genes demonstrates that the two classes of mutants do not have the same effect on the formation of the dl gradient. Dominant ventralizing alleles of dorsal group genes affect the slope of the gradient in a linear fashion such that if more than one positional value is represented, the high point and low point of the gradient are always at opposite extremes of the axis. In the strongest case, the entire axis assumes the ventral-most fate, the mesoderm (Anderson et al. 1985a; Roth et al. 1991). In grk, Egfr, and cni mutant embryos, the slope of the gradient is not affected, rather there is an expansion of the mesoderm and a deletion of dorsal pattern elements that can be described as a dorsal shift in the gradient. Furthermore, in the strongest cases, the mesoderm does not occupy the entire axis as in the strongest ventralizing allele of the dorsal group genes. Instead, the mesoderm splits into two groups of cells that form independent ventral furrows, and a new domain of ventral ectoderm is intercalated between them (Schüpbach 1987; Roth and Schüpbach 1994). In these embryos, the $d l$ gradient is no longer monotonic, thus, reduction in Egfr signaling in the ovary is not simply leading to a corresponding expansion of the $d l$ gradient.

The nonlinear ventralization produced by grk, Egfr, and cni mutants implies that there is further refinement of the dorsal-ventral pattern between Egfr and Tl, and the de novo generation of pattern in the embryonic axis suggests that this refinement involves a lateral inhibition process (Roth and Schüpbach 1994). This process could act at one of two points in the pathway. On the one hand, Egfr may roughly restrict the expression or activation of wind, nud, and pip to ventral follicle cells, and this prepattern may be refined by lateral inhibition be- 


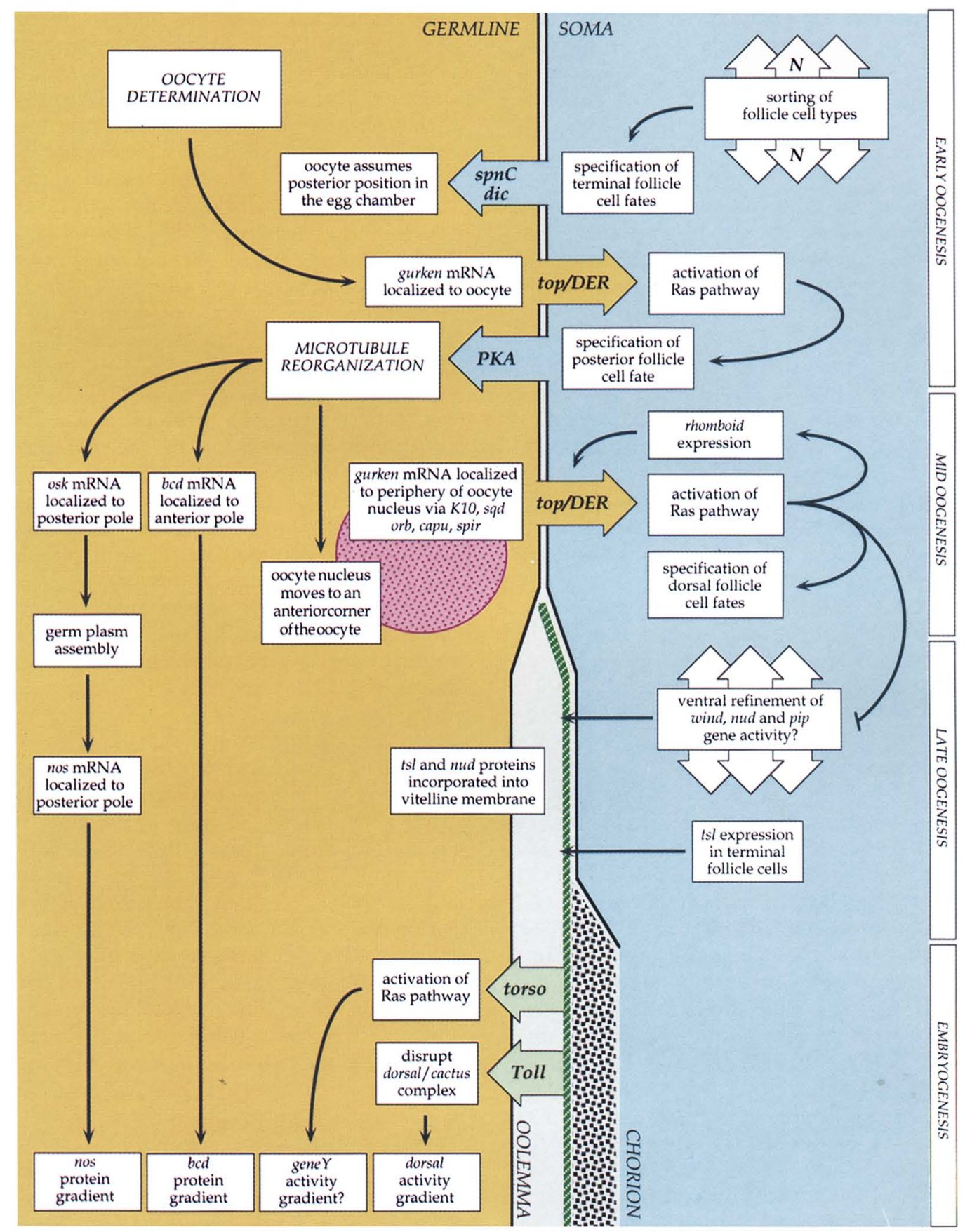

Figure 2. Schematic diagram of the network of intercellular signaling processes leading to the establishment of anterior-posterior and dorsal-ventral polarity during Drosophila oogenesis. As indicated to the right, the developmental stage runs along the vertical axis starting at the top with egg chamber formation and ending at the bottom with early embryogenesis. The germ-line and somatic tissues are colored yellow and blue, respectively, the oocyte nucleus is purple and the vitelline membrane green. Signaling between germ line and soma is indicated with broad yellow arrows, whereas signaling between soma and germ line is indicated with broad blue arrows. Green arrows indicate transmission of delayed signals from the vitelline membrane to the embryo. Local cell-cell interactions are indicated with boxes flanked with a trio of arrows.

tween the serine proteases in the perivitelline space. Alternatively, Egfr could act to restrict a secondary patterning system in the ventral follicle cells that, in turn, activates wind, nud, and pip in a refined pattern that is directly communicated to $T l$ via the serine proteases. As the latter model requires interaction between follicle cells, it predicts that another intercellular signaling system is operating between Egfr and Tl. The nature of this signaling system awaits identification of genes that are involved in the refinement process. 


\section{Conclusion: a chronology}

Although each of the intercellular signaling events discussed above has its own unique consequences, in the context of the living organism, these events form an integrated spatio-temporal network (Fig. 2). In the germarium, germ-line cysts consisting of 15 nurse cells and a single oocyte, are produced by mitotic division of germline stem cells, and the cysts are enveloped in an epithelium of somatic follicle cells. Notch signaling between the somatic cells distinguishes different cell types within the epithelium, including the terminal follicle cells and stalk cells. Another intercellular signaling process between follicle cells and the presumptive oocyte, which may involve the spnC and dic genes, results in the posterior placement of the oocyte within the germ-line cluster and establishes anterior-posterior asymmetry in the egg chamber. These early events give rise to the geometry of oocyte, nurse cells, and follicle cells that will facilitate later signaling events.

The anterior-posterior patterning of follicle cells and the oocyte is regulated by bidirectional signaling between germ line and soma. From the time the oocyte is determined, grk mRNA is localized to it, and this localization confines grk activity to the posterior of the germline cluster. grk signals to the adjacent terminal follicle cells via Egfr and the Ras pathway, and as a consequence, these cells adopt a posterior follicle cell fate. The posterior follicle cells then generate a second signal back to the oocyte, mediated by the PKA gene, that induces a reorganization of the microtubules in the ooplasm. This microtubule reorganization leads to the localization of $b c d$ mRNA to the anterior pole and osk mRNA to the posterior pole. Once localized to the posterior pole, osk directs the stepwise assembly of the germ plasm, eventually recruiting the nos mRNA. The localized $b c d$ and nos mRNAs will serve as sources for protein gradients in the embryo that will direct patterning in the segmented region of the embryo.

The reorganization of the microtubule network also directs the movement of the oocyte nucleus to a corner of the anterior cortex, and this event defines the future dorsal side of the egg and embryo. At this time grk mRNA is localized to the periphery of the oocyte nucleus, and sends a second signal to the adjacent follicle cells, again via Egfr and the Ras pathway, which leads to dorsal follicle cell differentiation. Activation of Egfr at this stage induces localized expression of rho, which then appears to enhance signaling on the dorsal side. This signal may also restrict the activity of a second intercellular signaling system to ventral follicle cells. This as-yet-uncharacterized system may act to refine the more general patterning of the follicle cell epithelium by Egfr, and is involved in refining the activity of somatic dorsal group genes.

The somatic dorsal group genes, wind, nud, and pip, and the somatic terminal gene, $t s l$ produce stable, asymmetric cues in the egg that restrict activation of the trans-membrane receptors $T 1$ and tor in early embryogenesis. Localized activity of the somatic dorsal group genes on the ventral side of the embryo results in the graded production of the $T 1$ ligand $s p z$. Activation of $T 1$ leads to the disruption of the $d l /$ cact complex and formation of the $d l$ protein gradient. Localized $t s l$ at the poles of the embryo results in the activation of the tor ligand, trk. The tor signal is transduced in the embryo via the Ras pathway, which leads to the activation of the postulated terminal morphogen geneY. The $d l$ gradient and gene $Y$ direct patterning along the dorsal-ventral axis and at the termini, respectively, and in combination with the $b c d$ and nos gradients, specify the complete body plan of the Drosophila embryo.

\section{Acknowledgments}

We would like to thank C. Klämbt for the pnt ${ }^{r M 254}$ enhancer trap line, Laura Nilson, Amanda Norvell, Arno Müller, and Cheryl van Buskirk for critical reading of the manuscript, and all of our colleagues in the Wieschaus and Schüpbach laboratories for stimulating discussions. We would also like to thank our outside reviewers for their helpful comments and suggestions. We regret that because of space limitations we were unable to cite all of the important work that has contributed to our understanding of intercellular signaling during oogenesis. T.S. is an Associate Investigator and R.P.R. a Postdoctoral Associate of the Howard Hughes Medical Institute.

\section{References}

Anderson, K.V., G. Jürgens, and C. Nüsslein-Volhard. 1985a. Establishment of dorsal-ventral polarity in the Drosophila embryo: Genetic studies on the role of the Toll gene product. Cell 42: 779-789.

Artavanis-Tsakonas, S., K. Matsuno, and M.E. Fortini. 1995. Notch signaling. Science 268: 225-232.

Bier, E., L.Y. Jan, and Y.N. Jan. 1990. rhomboid, a gene required for dorsoventral axis establishment and peripheral nervous system development in Drosophila melanogaster. Genes \& Dev. 4: 190-203.

Bourne, H.R., D.A. Sanders, and F. McCormick. 1990. The GTPase superfamily: A conserved switch for diverse cell functions. Nature 348: 125-132.

Brand, A.H. and N. Perrimon. 1994. Raf acts downstream of the EGF receptor to determine dorsoventral polarity during Drosophila oogenesis. Genes \& Dev. 8: 629-639.

Casanova, J., M. Furriols, C.A. McCormick, and G. Struhl. 1995. Similarities between trunk and spätzle, putative extracellular ligands specifying body pattern in Drosophila. Genes \& Dev. 9: 2539-2544.

Chang, F. and P. Nurse. 1996. How fission yeast fission in the middle. Cell 84: 191-194.

Chang, F., A. Wollard, and P. Nurse. 1996. Isolation and characterization of fission yeast mutants defective in the assembly and placement of the contractile actin ring. J. Cell Sci. 109: 131-142.

Chou, T.-B., E. Noll, and N. Perrimon. 1993. Autosomal $P\left[\mathrm{OVO}^{D 1}\right.$ ] dominant female-sterile insertions in Drosophila and their use in generating germ-line chimeras. Development 119: 1359-1369.

Christerson, L.B. and D.M. McKearin. 1994. orb is required for anteroposterior and dorsoventral patterning during Drosophila oogenesis. Genes \& Dev. 8: 614-628.

Clark, I., E. Giniger, H. Ruohola-Baker, L.Y. Jan, and Y.N. Jan. 1994. Transient posterior localization of a kinesin fusion 
protein reflects anteroposterior polarity of the Drosophila oocyte. Curr. Biol. 4: 289-300.

Clifford, R. and T. Schüpbach. 1992. The torpedo(DER) receptor tyrosine kinase is required at multiple times during Drosophila embryogenesis. Development 115: 853-872.

Cummings, C.A. and C. Cronmiller. 1994. The daughterless gene functions together with Notch and Delta in the control of ovarian follicle development in Drosophila. Development 120: $381-394$.

Diaz-Benjumea, F. J. and A. García-Bellido. 1990. Behaviour of cells mutant for an EGF receptor homologue of Drosophila in genetic mosaics. Proc. R. Soc. London 242: 36-44.

Diederich, R. J., K. Matsuno, H. Hing, and S. Artavanis-Tsakonas. 1994. Cytosolic interaction between deltex and Notch ankyrin repeats implicates deltex in the Notch signaling pathway. Development 120: 473-481.

Emmons, S., H. Phan, J. Calley, W. Chen, B. James, and L. Manseau. 1995. cappuccino, a Drosophila maternal effect gene required for polarity of the egg and embryo, is related to the vertebrate limb deformity locus. Genes \& Dev. 9: 24822494.

Erdélyi, M., A.-M. Michon, A. Guichet, J.B. Glotzer, and A. Ephrussi. 1995. Requirement for Drosophila cytoplasmic tropomyosin in oskar mRNA localization. Nature 377: 524 527.

Fehon, R.G., P.J. Kooh, I. Rebay, C.L. Regan, T. Xu, M.A.T. Muskavitch, and S. Artavanis-Tsakonas. 1990. Molecular interactions between the protein products of the neurogenic loci Notch and Delta, two EGF-homologous genes in Drosophila. Cell 61: 523-534.

Fleming, R. J., T.N. Scottgale, R.J. Diederich, and S. ArtavanisTsakonas. 1990. The gene Serrate encodes a putative EGFlike transmembrane protein essential for proper ectodermal development in Drosophila melanogaster. Genes \& Dev. 4: $2188-2201$.

Fortini, M.E. and S. Artavanis-Tsakonas. 1994. The Suppressor of hairless protein participates in Notch receptor signaling. Cell 79: 273-282.

Frey, A., K. Sander, and H. Gutzeit. 1984. The spatial arrangement of germ line cells in ovarian follicles of the mutant dicephalic in Drosophila melanogaster. Wilhelm Roux's Arch. Dev. Biol. 193: 388-393.

Gaul, U., H. Mardon, and G.M. Rubin. 1992. A putative Ras GTPase activating protein acts as a negative regulator of signaling by the sevenless receptor tyrosine kinase. Cell 68: $1007-1019$.

Gillespie, D.E. and C.A. Berg. 1995. homeless is required for RNA localization in Drosophila oogenesis and encodes a new member of the DE-H family of RNA-dependent ATPases. Genes \& Dev. 9: 2495-2508.

Gonzáles-Reyes, A., and R.D. St. Johnston. 1994. Role of oocyte position in establishment of anterior-posterior polarity in Drosophila. Science 266: 639-642.

Gonzáles-Reyes, A., H. Elliott, and R.D. St. Johnston. 1995. Polarization of both major body axes in Drosophila by gurkentorpedo signalling. Nature 375: 654-658.

Goode, S., D. Wright, and A.P. Mahowald. 1992. The neurogenic locus brainiac cooperates with the Drosophila EGF receptor to establish the ovarian follicle and to determine its dorsalventral polarity. Development 116: 177-192.

Gutzeit, H. 1986. The role of microtubules in the differentiation of ovarian follicles during vitellogenesis in Drosophila. Wilhelm Roux's Arch. Dev. Biol. 195: 173-181.

Hartenstein, V. and J.W. Posakony. 1990. A dual function of the Notch gene in Drosophila sensillum development. Dev. Biol. 142: 13-30.
Hong, C.C. and C. Hashimoto. 1995. An unusual mosaic protein with a protease domain, encoded by the nudel gene, is involved in defining embryonic dorsoventral polarity in Drosophila. Cell 82: 785-794.

Hsu, J.-C. and N. Perrimon. 1994. A temperature-sensitive MEK mutation demonstrates the conservation of the signaling pathways activated by receptor tyrosine kinases. Genes \& Dev. 8: 2176-2187.

Kammermeyer, K.L. and S.C. Wadsworth. 1987. Expression of Drosophila epidermal growth factor receptor homologue in mitotic cell populations. Development 100: 201-210.

Kelley, R.L. 1993. Initial organization of the Drosophila dorsoventral axis depends on an RNA-binding protein encoded by the squid gene. Genes \& Dev. 7: 948-960.

Kidd, S., M.R. Kelley, and M.Y. Young. 1986. Sequence of the Notch locus of Drosophila melanogaster: Relationship of the encoded protein to mammalian clotting and growth factors. Mol. Cell. Biol. 6: 3094-3108.

Koch, E.A. and R.H. Spitzer. 1983. Multiple effects of colchicine on oogenesis in Drosophila: Induced sterility and switch of potential oocyte to nurse-cell developmental pathway. Cell Tissue Res. 228: 21-32.

Kopczynski, C.C., A.K. Alton, K. Fechtel, P.J. Kooh, and M.A.T. Muskavitch. 1988. Delta, a Drosophila neurognic gene, is transcriptionally complex and encodes a protein related to blood coagulation factors and epidermal growth factor of vertebrates. Genes \& Dev. 2: 1723-1735.

Lane, M.E. and D. Kalderon. 1994. RNA localization along the anteroposterior axis of the Drosophila oocyte requires PKAmediated signal transduction to direct normal microtubule organization. Genes \& Dev. 8: 2986-2995.

Lantz, V., L. Ambrosio, and P. Schedl. 1992. The Drosophila orb gene is predicted to encode sex-specific germline RNA-binding proteins and has localized transcripts in ovaries and early embryos. Development 115: 75-88.

Lantz, V., J.S. Chang, J.I. Horabin, D. Bopp, and P. Schedl. 1994. The Drosophila orb RNA-binding protein is required for the formation of the egg chamber and establishment of polarity. Genes \& Dev. 8: 598-613.

Li, M.-G., M. McGrail, M. Serr, and T.S. Hayes. 1994. Drosophila cytoplasmic dynein, a microtubule motor that is asymmetrically localized in the oocyte. $/$. Cell Biol. 126: 14751494.

Livneh, E., L. Glazer, D. Segal, J. Schlessinger, and B.-Z. Shilo. 1985. The Drosophila EGF receptor gene homolog: Conservation of both hormone binding and kinase domains. Cell 40: 599-607.

Lu, X., L.A. Perkins, and N. Perrimon. 1993. The torso pathway in Drosophila: A model system to study receptor tyrosine kinase signal transduction. Development (Suppl.): 47-56.

Manseau, L.J. and T. Schüpbach. 1989. cappuccino and spire: Two unique maternal-effect loci required for both the anteroposterior and dorsoventral patterns of the Drosophila embryo. Genes \& Dev. 3: 1437-1452.

Mark, G.E., R.J. MacIntyre, M.E. Digan, L. Ambrosio, and N. Perrimon. 1987. Drosophila melanogaster homologs of the raf oncogene. Mol. Cell. Biol. 7: 2134-2140.

Matunis, E.L., R. Kelley, and G. Dreyfuss. 1994. Essential role for a heterogeneous nuclear ribonucleoprotein (hnRNP) in oogenesis: hrp40 is absent from the germ line in the dorsoventral mutant squid. Proc. Natl. Acad. Sci. 91: 2781-2784.

Morisato, D. and K.V. Anderson. 1994. The spätzle gene encodes a component of the extracellular signaling pathway establishing the dorsal-ventral pattern of the Drosophila embryo. Cell 76: 677-688.

__ 1995. Signaling pathways that establish the dorsal-ven- 
tral pattern of the Drosophila embryo. Annu. Rev. Genetics 29: 371-399.

Neuman-Silberberg, F. S. and T. Schüpbach. 1993. The Drosophila dorsoventral patterning gene gurken produces a dorsally localized RNA and encodes a TGF $\alpha$-like protein. Cell 75: 165-174.

1994. Dorsoventral axis formation in Drosophila depends on the correct dosage of the gene gurken. Development 120: 2457-2463.

Nishida, Y., M. Hata, T. Ayaki, H. Ryo, M. Yamagata, K. Shimizu, and Y. Nishizuka. 1988. Proliferation of both somatic and germ cells is affected in the Drosophila mutants of raf proto-oncogene. EMBO J. 7: 775-781.

Parks, A.L. and M.A.T. Muskavitch. 1993. Delta function is required for bristle organ determination and morphogenesis in Drosophila. Dev. Biol. 157: 484-496.

Peifer, M., S. Orsulic, D. Sweeton, and E. Wieschaus. 1993. A role for the Drosophila segment polarity gene armadillo in cell adhesion and cytoskeletal integrity during oogenesis. Development 118: 1191-1207.

Pokrywka, N.J. and E.C. Stevenson. 1991. Microtubules mediate the localization of bicoid RNA during Drosophila oogenesis. Development 113: 55-66.

Prost, E., F. Deryckere, C. Roos, M. Haenlin, V. Pantesco, and E. Mohier. 1988. Role of the oocyte nucleus in determination of the dorsoventral polarity of Drosophila as revealed by molecular analysis of the K10 gene. Genes \& Dev. 2: 891-900.

Raz, E., E.D. Schejter, and B.-Z. Shilo. 1991. Interallelic complementation among DER/flb alleles: Implications for the mechanism of signal transduction by receptor-tyrosine kinases. Genetics 129: 191-201.

Rebay, I., R.J. Fleming, R.G. Fehon, L. Cherbas, P. Cherbas, and S. Artavanis-Tsakonas. 1991. Specific EGF Repeats of Notch mediate interactions with Delta and Serrate: Implications for Notch as a multifunctional receptor. Cell 67: 687-699.

Rongo, C. and R. Lehmann. 1996. Regulated synthesis, transport and assembly of the Drosophila germ plasm. Trends Genet. 12: 102-109.

Roth, S. 1993. Mechanisms of dorsal-ventral axis determination in Drosophila embryos revealed by cytoplasmic transplantations. Development 117: 1385-1396.

- 1994. Proteolytic generation of a morphogen. Curr. Biol. 4: 755-757.

Roth, S. and T. Schüpbach. 1994. The relationship between ovarian and embryonic dorsoventral patterning in Drosophila. Development 120: 2245-2257.

Roth, S., Y. Hiromi, D. Godt, and C. Nüsslein-Volhard. 1991. cactus, a maternal gene required for proper formation of the dorsoventral morphogen gradient in Drosophila embryos. Development 112: 371-388.

Roth, S., F.S. Neuman-Silberberg, G. Barcelo, and T. Schüpbach. 1995. cornichon and the EGF receptor signaling process are necessary for both anterior-posterior and dorsal-ventral pattern formation in Drosophila. Cell 81: 967-978.

Ruohola, H., K.A. Bremer, D. Baker, J.R. Swedlow, L.Y. Jan, and Y.N. Jan. 1991. Role of neurogenic genes in establishment of follicle cell fate and oocyte polarity during oogenesis in Drosophila. Cell 66: 433-449.

Ruohola-Baker, H., E. Grell, T.-B. Chou, D. Baker, L.Y. Jan, and Y.N. Jan. 1993. Spatially localized rhomboid is required for establishment of the dorsal-ventral axis in Drosophila oogenesis. Cell 73: 953-965.

Rutledge, B.J., K. Zhang, E. Bier, Y.N. Jan, and N. Perrimon. 1992. The Drosophila spitz gene encodes a putative EGF-like growth factor involved in dorsal-ventral axis formation and neurogenesis. Genes \& Dev. 6: 1503-1517.
Savant-Bhonsale, S. and D.J. Montell. 1993. torso-like encodes the localized determinant of Drosophila terminal pattern formation. Genes \& Dev. 7: 2548-2555.

Schüpbach, T. 1987. Germ line and soma cooperate during oogenesis to establish the dorsoventral pattern of egg shell and embryo in Drosophila melanogaster. Cell 49: 699-707.

Schweitzer, R., R. Howes, R. Smith, B.-Z. Shilo, and M. Freeman. 1995a. Inhibition of Drosophila EGF receptor activation by the secreted protein Argos. Nature 376: 699-702.

Schweitzer, R., M. Shaharabany, R. Seger, and B.-Z. Shilo. 1995b. Secreted spitz triggers the DER signaling pathway and is a limiting component in embryonic ventral ectoderm determination. Genes \& Dev. 9: 1518-1529.

Spradling, A.C. 1993. Developmental genetics of oogenesis. In The development of Drosophila melanogaster (ed. M. Bate and A. Martinez Arias), pp. 1-70. Cold Spring Harbor Laboratory Press, Cold Spring Harbor, NY.

St. Johnston, R.D. and C. Nüsslein-Volhard. 1992. The origin of pattern and polarity in the Drosophila embryo. Cell 68: 201219.

St. Johnston, R.D., W. Driever, T. Berleth, S. Richstein, and C. Nüsslein-Volhard. 1989. Multiple steps in the localization of bicoid RNA to the anterior pole of the Drosophila oocyte. Development (Suppl.) 107: 13-19.

Stevens, L.M., H.G. Fronhöfer, M. Klingler, and C. NüssleinVolhard. 1990. Localized requirement for torso-like expression in follicle cells for development of terminal anlagen of the Drosophila embryo. Nature 346: 660-662.

Sturtevant, M.A., M. Roark, and E. Bier. 1993. The Drosophila rhomboid gene mediates the localized formation of wing veins and interacts genetically with components of the EGF-R signaling pathway. Genes \& Dev. 7: 961-973.

Theurkauf, W.E., S. Smiley, M.L. Wong, and B.M. Alberts. 1992. Reorganization of the cytoskeleton during oogenesis: Implications for axis specification and intercellular transport. Development 115: 923-936.

Thomas, U., S.A. Speicher, and E. Knust. 1991. The Drosophila gene Serrate encodes and EGF-like transmembrane protein with a complex expression pattern in embryos and wing discs. Development 111: 749-761.

Vässin, H., K.A. Bremer, E. Knust, and J.A. Campos-Ortega. 1985. The neurogenic gene Delta of Drosophila melanogaster is expressed in neurogenic territories and encodes a putative transmembrane protein with EGF-like repeats. EMBO I. 6: 3431-3440.

Wadsworth, S.C., W.S. Vincent, and S. Bilodeau-Wentworth. 1985. A Drosophila genomic sequence with homology to human epidermal growth factor receptor. Nature 314: 178180.

Wharton, K.A., K.M. Johansen, T. Xu, and S. Artavanis-Tsakonas. 1985. Nucleotide sequence from the neurogenic locus Notch implies a gene product that shares homology with proteins containing EGF-like repeats. Cell 43: 567-581.

Wieschaus, E. 1979. $f_{S}(1) K 10$, a female sterile mutation altering the pattern of both the egg coverings and the resultant embryos in Drosophila. In Cell lineage, stem cell and cell differentiation, (ed. N. le Douarin), pp. 291-302. Elsevier/ North-Holland Biomedical Press, New York, NY.

Wieschaus, E., J.L. Marsh, and W. Gehring. 1978. fs(1)K10, a germline-dependent female sterile mutation causing abnormal chorion morphology in Drosophila melanogaster. Wilhelm Roux's Arch. Dev. Biol. 184: 75-82. 


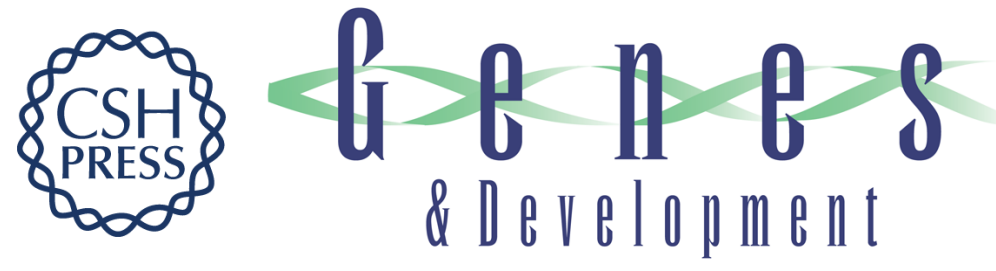

\section{Intercellular signaling and the polarization of body axes during Drosophila oogenesis.}

R P Ray and T Schüpbach

Genes Dev. 1996, 10:

Access the most recent version at doi:10.1101/gad.10.14.1711

References This article cites 77 articles, 41 of which can be accessed free at:

http://genesdev.cshlp.org/content/10/14/1711.full.html\#ref-list-1

License

Email Alerting

Service

Receive free email alerts when new articles cite this article - sign up in the box at the top right corner of the article or click here.

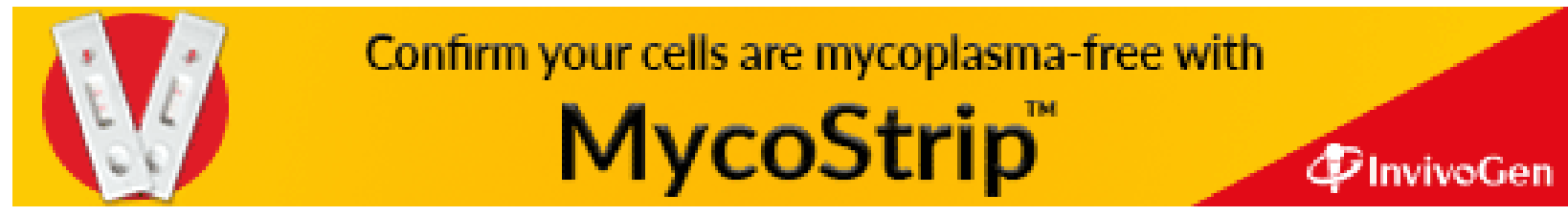

